
PERONISMO (1946-1955)

\title{
ONDE HABITA A DEMOCRACIA? OS DEBATES PARLAMENTARES SOBRE O REGIME MUNICIPAL DA CIDADE DE BUENOS AIRES DURANTE O PRIMEIRO PERONISMO (1946-1955)
}

\section{WHERE DOES DEMOCRACY RESIDE? THE PARLIAMENTARY DEBATES ON THE MUNICIPAL GOVERNMENT IN THE CITY OF BUENOS AIRES DURING THE FIRST PERONIST REGIME (1946-1955)}

\section{OÙ HABITE LA DÉMOCRATIE ? LES DÉBATS PARLEMENTAIRES SUR LE RÉGIME MUNICIPAL DE LA VILLE DE BUENOS AIRES DURANT LE PREMIER PÉRONISME (1946-1955)}

民主摆放在哪里?

阿根廷皮隆政府(1946-1955) 期间议会关于布宜诺斯艾利斯市政府的政体问题的辩论

DOI: 10.5533/1984-2503-20135305

Romina Berman ${ }^{1}$

\section{RESUMEN}

El artículo explora las propuestas que el Partido Peronista y la Unión Cívica Radical presentaron en el Congreso entre 1946 y 1955 en torno al régimen de gobierno de la Ciudad de Buenos Aires. Dicho distrito comportaba un carácter singular por su condición de capital de la República. Esto incitaba debates sobre las prerrogativas que debían tener sus instituciones comunales, y en coyunturas históricas particulares estas discusiones se agudizaban. Así sucedió con el regreso a la constitucionalidad en 1946. De esta forma, se analizan las iniciativas desplegadas por los partidos con representación parlamentaria, contemplando además otra peculiaridad: el cierre ininterrumpido del Concejo Deliberante durante toda la década.

Palabras clave: Régimen municipal, Ciudad de Buenos Aires, Peronismo, Proyectos de ley.

\footnotetext{
1 Becaria doctoral CONICET. Investigadora en formación del Centro de Estudios de Historia Política, Universidad Nacional de General San Martín. Doctoranda en Ciencias Sociales por la Universidad de Buenos Aires. Docente de la Escuela de Política y Gobierno, UNSAM. Email: rominaberman@gmail.com
} 


\section{RESUMO}

O artigo explora as propostas que o Partido Peronista e a União Cívica Radical apresentaram no Congresso entre 1946 e 1955 em torno do regime de governo da cidade de Buenos Aires. O distrito apresentava caráter singular por sua condição de capital da República. Isto incitava debates sobre as prerrogativas que deviam ter suas instituições comuns, e em conjunturas históricas particulares estas discussões se intensificavam. Assim ocorreu com o regresso à constitucionalidade em 1946. Desta forma, são analisadas as iniciativas empregadas pelos partidos com representação parlamentar, contemplando-se ainda outra peculiaridade: o fechamento ininterrupto da Câmara de Vereadores deliberante durante toda a década.

Palavras-chave: Regime municipal, Cidade de Buenos Aires, Peronismo, Projetos de lei.

\section{ABSTRACT}

The article explores the proposals that the Peronist Party and the Radical Civic Union made in Congress between 1946 and 1955 concerning the governmental regime in the city of Buenos Aires. As the district was unique in nature due to being the country's capital, this provoked debate on the prerogatives of its common institutions, and at particular moments in history these debates were intensified, such as occurred with the return to a constitution in 1946. We thus analyse the initiatives employed by the parties with parliamentary representation, and also consider a further peculiarity: the extended closure of the deliberating Chamber of Councilors throughout the entire decade.

Key words: Municipal Government, City of Buenos Aires, Peronism, Draft Bills.

\section{RÉSUMÉ}

Cet article explore les propositions que le Parti péroniste et I'Union civique radicale présentèrent au Congrès entre 1946 et 1955 en ce qui concerne le régime de gouvernement de la ville de Buenos Aires. Le district présentait un caractère singulier en raison de sa condition de capitale de la République. Cela provoqua des débats sur les prérogatives dont devaient jouir ses institutions communes, des débats qui s'intensifièrent dans le cadre d'une conjoncture historique particulière. C'est ce qui se passa en 1946 lors du retour à la constitutionnalité. Nous analyserons donc les initiatives prises par les partis 
jouissant d'une représentation parlementaire, tout en prenant compte une autre particularité : la fermeture ininterrompue du Conseil municipal durant toute cette décennie. Mots-clés: Régime municipal, Ville de Buenos Aires, Péronisme, Projets de loi.

\section{摘要}

本论文分析了皮隆党(Partido Peronista)和市民激进联盟(União Cívica Radical) 在19461955年期间在阿根廷国会针对布宜诺斯爱利斯市政府的政体问题的多个辩论议案。由于布 宜诺斯爱利斯是阿根廷的首都, 其特殊的地位引发了关于布宜市政府的政体问题的辩论, 并 且在特定的历史环境中辩论不断加强，例如发生在1946年的回归宪政运动。本论文分析了 各个党派在国会辩论中提出的关于布宜市政体问题的议案，同时对当时的特殊现象一 布宜市议会在此十年期间连续不间断的闭会一进行分析研究。

关键字：市政体制，布宜诺斯艾利斯市，皮隆主义，法律提案。

\section{La Ciudad de Buenos Aires, un distrito particular}

Las iniciativas que presentaron el justicialismo y la oposición parlamentaria en torno al esquema institucional de la Capital Federal, merecen ser analizadas a la luz de las dos tesis que dominaron la discusión sobre la materia hasta la reforma constitucional de 1994, que planteó nuevas condiciones para el distrito. ${ }^{2}$ Encontramos por un lado la tesis de limitación de poderes federales y correlativa amplitud del gobierno local. Sus postulados distinguían entre gobierno político y régimen municipal o administrativo: mientras que el primero suponía la jefatura política de la capital de un país, el segundo implicaba la jefatura de la municipalidad. De este modo, se argumentaba que Buenos Aires había contado con un régimen municipal antes de ser declarada Capital de la Nación, y consecuentemente le correspondía un gobierno autónomo. Por otro lado, existía la tesis restrictiva o de amplitud exclusiva de las potestades federales, que se apoyaba en lo dispuesto por el texto constitucional de 1853 y ha resultado predominante. El inciso $27^{\circ}$

\footnotetext{
${ }^{2}$ Para las interpretaciones constitucionales en torno a la Capital Federal ver Passalacqua, Eduardo $\mathrm{H}$. (1996). "La autonomía de Buenos Aires. Un ensayo de historia institucional sobre las ideas y las formas de un cambio, y una tentativa de descripción. Resultados actuales y potenciales". In Ciudad de Buenos Aires. Gobierno y descentralización, Buenos Aires: CEA-Oficina de Publicaciones del CBC, Universidad de Buenos Aires.
} 
del artículo 67 indicaba que el Congreso Nacional debía ejercer una legislación exclusiva en todo el territorio de la Capital, mientras que el inciso $3^{\circ}$ del artículo 86 expresaba que el Presidente era su jefe inmediato y local. En este sentido, la normativa no exigía un gobierno autónomo ni electivo, y asimismo habilitaba al Primer Mandatario a intervenir tanto la Intendencia como la legislatura local.

La reforma constitucional efectuada en 1949 no implicó modificaciones radicales en el texto. Los convencionales peronistas expresaron que sólo había que precisar lo estipulado por la Carta Magna del '53 para evitar lecturas maliciosas que pudieran surgir a partir de las ambigüedades presentes. De este modo, las potestades federales se mantuvieron, y se adicionaron frases aclaratorias que puntualizaron la concentración de facultades en aquellas, especialmente en el Poder Ejecutivo. Esto implicó, por ejemplo, que el Congreso en calidad de legislatura local sólo se encargara de debatir cuestiones tributarias y de presupuesto, y que el Presidente retuviera prerrogativas que antaño habían estado en manos del parlamento nacional. ${ }^{3}$

Por otra parte, debe agregarse que, aunque la Carta Magna no le confería a la Ciudad de Buenos Aires estatus provincial, muchas veces éste se daba de facto. Entonces en los hechos adquiría un alma de provincia que le permitía, entre otras cosas, contar con representación en el Congreso. En consecuencia, aquellos que abogaban por la autonomía local aludían al artículo 5 de la Constitución que establecía que cada provincia dictaría su propia carta acorde al texto nacional. Esta debía asegurar entre otras cosas la existencia del régimen municipal para sus localidades. De esta forma, el escenario detallado abría discusiones difíciles de saldar, que pueden verse reflejadas en los encontrados puntos de vista que se expondrán más adelante, como así también en la precaria estabilidad institucional que padeció la ciudad desde su federalización hasta inicios de la década del cuarenta.

\footnotetext{
${ }^{3}$ Para un análisis más detallado sobre la estructura institucional de la Capital Federal en la reforma constitucional de 1949 véase Berman, Romina (2010). "Un buen gobierno del distrito federal para la paz de la nación: reflexiones acerca del régimen municipal para la Ciudad de Buenos Aires en la reforma de la Constitución Nacional de 1949". In Segundo Congreso de Estudios sobre el Peronismo (1943-1976), Red de Estudios sobre Peronismo, Universidad Nacional de Tres de Febrero.
} 


\section{Antecedentes}

\subsection{Los años '20 y '30: la centralidad del Concejo Deliberante y una tensa relación entre poderes}

La ley orgánica municipal 1.260 sancionada en 1882 dispuso que la Municipalidad de la Capital fuera conformada por un Departamento Ejecutivo y un Concejo Deliberante. El primero quedaba a cargo de un funcionario designado por el Presidente con acuerdo del Senado, mientras que los concejales eran elegidos a través de un sufragio restringido. La modificación de la norma en 1917 significó la instauración del sufragio universal masculino para la conformación de la legislatura comunal. Esta medida, sancionada en consonancia con la ley Saénz Peña de 1912, abrió un novedoso panorama para los protagonistas del juego político local. La ampliación del cuerpo de votantes condujo a los partidos políticos nacionales a desarrollar una importante estructura a nivel local. Principalmente el Partido Socialista y la Unión Cívica Radical, interesados en captar a los nuevos potenciales electores, dispusieron su presencia territorial a partir de su propagación por los distintos barrios. Los partidos vecinales locales también se volcaron a esta conquista, aunque con una baja performance. Esta especie de organización capilar, junto con el acceso expandido a los comicios, generó también en las asociaciones barriales nuevas estrategias a la hora de hacer oír sus reclamos. Estas circunstancias dieron lugar a una superposición de prácticas electorales, lenguajes políticos, lazos clientelares e instituciones de la sociedad civil. La extrema cercanía entre representante y representado permitió la conformación de redes en las que la dimensión políticoinstitucional se entremezclaba con la sociabilidad barrial. Esta dinámica implicaba alianzas cambiantes: entre las asociaciones vecinales y el Concejo, entre éstas y el Intendente, y además entre ambas ramas de gobierno sin importar la pertenencia partidaria (así lo evidencia por ejemplo el negociado de los transportes, en el que concejales radicales prestaron conformidad al ejecutivo local conservador a cambio de 
recursos económicos. ${ }^{4}$ También el 'Affaire CHADE', que involucró a políticos locales de diversas agrupaciones en los turbios debates sobre la electricidad). ${ }^{5}$

Tras la reforma del '17 no se modificó la designación del Intendente por parte del Ejecutivo Nacional. Por lo tanto, la legitimidad de origen de ambas autoridades no era la misma. Consecuentemente, podía suceder que cada órgano respondiera a un color político distinto, situación que generaba competencias por las áreas de control que se traducían en conflictos institucionales. Incluso con un Concejo con mayoría oficialista, éste podía no ajustarse a lo impartido por el Primer Mandatario a través de su delegado, el Intendente. Así es que a la hora de zanjar diferencias entre los órganos comunales, una solución era la disolución del Concejo por parte del Presidente, en su calidad de jefe inmediato de la Capital. En este sentido, desde la federalización de la ciudad en 1880 hasta los años 40, la labor de éste tuvo idas y vueltas, intercalándose períodos de actividad con otros de suspensión de la misma. En este último caso, se ponía en reemplazo una comisión interventora de vecinos nombrados por el Presidente, que en algunas oportunidades debió ser ratificada por el Senado. Estos vaivenes se materializaron en variaciones a la ley orgánica: a veces se derogó y luego fue repuesta, en otras oportunidades sufrió pequeñas innovaciones que no vulneraron su carácter general. ${ }^{6}$ Tanto conservadores como radicales hicieron uso de este mecanismo mientras ocuparon la Primera Magistratura, teniendo un Concejo con mayoría propia como así también cuando éste era controlado por una agrupación política adversa.

Esta dinámica se mantuvo hasta que en 1941 el Vicepresidente en ejercicio Castillo decretó la disolución de la legislatura, sustituyéndola por una comisión interventora. Tal escenario alentó la presentación de proyectos legislativos en pos de reestructurar el régimen de gobierno del distrito, mas el golpe de Estado perpetrado en 1943 paralizó el debate. El nuevo gobierno militar sellaría con su impronta los siguientes años de gestión de la ciudad.

\footnotetext{
${ }^{4}$ Véase Privitellio, Luciano de(2003). Vecinos y ciudadanos. Política y sociedad en la Buenos Airesde entreguerra, Buenos Aires: Siglo XXI

5 Para el "Affaire CHADE" véase Privitellio, Luciano de (2003). Op. Cit.; Ciria, Alberto (2000). "Política tradicional y política de masas". In Romero, José Luis y Romero, Luis Alberto (Eds.) (2000). Buenos Aires, Historia de cuatro siglos, Buenos Aires: Grupo Editor Altamira, t. 2.

${ }^{6}$ Véase la Ley Orgánica de la Municipalidad de la Ciudad de Buenos Aires (ley 1.260 con sucesivas modificaciones 1883-1958).
} 


\subsection{La Revolución de Junio: concentración de facultades en busca de la eficacia}

A pocos días de tomar el poder, el gobierno de facto afirmó la continuidad de la comisión de vecinos. Sin embargo, apenas doce días después mediante el decreto presidencial 1.299 del 28 de junio de 1943, dicho cuerpo se suprimió. Se argumentó que debía cederse el paso a una gestión más directa y ejecutiva, y que además debía promoverse un exhaustivo estudio sobre la organización municipal a efectos de dictar una nueva legislación acorde a las necesidades de la ciudad. El plan no prosperó más allá del entusiasta discurso inicial. La norma determinó que la Intendencia podía realizar los actos indispensables en los casos en que la ley exigiese una decisión del Concejo Deliberante, sometiendo sus decisiones a la aprobación del Ejecutivo Nacional. Posteriormente, el decreto 2.162 explicitó que las atribuciones de la rama legislativa comunal quedaban delegadas al Intendente, con algunas excepciones relativas al presupuesto, contrataciones y cuestiones impositivas. En septiembre de 1943 una nueva norma introdujo modificaciones en lo concerniente a las facultades del Departamento Ejecutivo. El decreto 9.381 concedía a aquel la posibilidad de concretar reasignaciones en el presupuesto, siempre que no importaran aumentos; la disposición pretendía agilizar la labor de las autoridades de la Comuna, evitando trámites innecesarios. Todas estas medidas se declaraban provisorias hasta tanto se restableciera la rama legislativa local, situación que tuvo lugar recién en 1958.

\section{Propuestas para gobernar la Capital Federal entre 1946 y 1955.}

\subsection{Los proyectos radicales: por la democracia, la autonomía y la reapertura del Concejo}

La restitución del Estado de Derecho en 1946 habilitó la discusión en el Congreso, vía válida para modificar las reglas del juego político. Por eso es que consideramos relevante detenernos en los proyectos allí presentados. Mas este punto de partida no debe conducir a entender a los bloques parlamentarios como actores monolíticos, 
especialmente en el caso de la Unión Cívica Radical bajo el peronismo clásico. ${ }^{7}$ El triunfo de Perón en las elecciones presidenciales marcó diferencias al interior del partido respecto de los pasos a seguir. $Y$ esto impactó en el desenvolvimiento de la agrupación en el recinto, que no siempre se pronunció de manera unívoca. No obstante, la salvaguarda de las instituciones democráticas funcionó como elemento aglutinante. En este sentido, hubo una posición uniforme en lo que concierne al tema de nuestro interés. Así fue que desde la llegada del peronismo al poder el radicalismo reivindicó un gobierno municipal para la Capital como derecho inalienable. A partir de la reapertura de las sesiones parlamentarias, los diputados radicales insistieron en el recinto con el cumplimiento de la ley orgánica. La bancada opositora, que se encontraba reducida a un pequeño grupo en la Cámara de Diputados, se manifestó en reiteradas ocasiones a propósito de las circunstancias que tenían lugar en la ciudad, que consideraban anómalas. $^{8}$ Las peticiones y denuncias del bloque radical no se limitaron al régimen de gobierno comunal. En 1946 el diputado Ernesto Sanmartino por la Capital Federal solicitó la exclusión del Intendente Emilio Siri. ${ }^{9}$ Además presentó un proyecto de declaración pidiendo la reposición de funcionarios cesantes, al mismo tiempo que cuestionaba los criterios aplicados para dichas separaciones, pues afirmaba que en algunos casos la causa residía en el previo apoyo brindado a la candidatura presidencial de Robustiano Patrón Costas. ${ }^{10}$ Oscar López Serrot, legislador por el mismo distrito, se mostró muy enérgico en sus presentaciones. A lo largo de la década realizó varios pedidos de informe al Ministerio del Interior, a cargo de Ángel Borlenghi, sobre la situación del gobierno de la ciudad. ${ }^{11}$ En esas ocasiones resaltó la indiferencia del Poder Ejecutivo frente a estas cuestiones. Aunque en la Comisión de Asuntos Municipales esta declaración había sido

\footnotetext{
${ }^{7}$ Para el desempeño de la Unión Cívica Radical bajo el primer peronismo véase Altamirano, Carlos (2002). "Ideologías políticas y debate cívico". In: Nueva Historia Argentina, Buenos Aires: Sudamericana, t. VIII, p. 207-255; Persello, Ana (2007). Historia del radicalismo, Buenos Aires: Edhasa.

${ }^{8}$ Las elecciones legislativas de 1946 determinaron una oposición parlamentaria conformada por el bloque radical de cuarenta y cuatro diputados, más cinco bancas distribuidas entre otras cuatro agrupaciones, mientras que el peronismo (sumando las bancas de las distintas fuerzas que lo componían) ganó ciento nueve. Tras los comicios de 1948 el peronismo conservó ciento diez de los ciento cincuenta y ocho diputados, el radicalismo continuó con sus cuarenta y cuatro, y otros cuatro partidos obtuvieron cada uno una banca. Las elecciones de 1951 implicaron ciento treinta y cinco legisladores peronistas, y catorce radicales. La última elección legislativa en 1954 otorgó ciento sesenta y un bancas al Partido Peronista, y doce a la Unión Cívica Radical. Véase Ajmechet, Sabrina. "Diputados nacionales 1946-1955". In Materiales para la Historia Política, Centro de Estudios de Historia Política. Disponible en: http://www.unsam.edu.ar/escuelas/politica/centro_historia_politica/materiales/Conformación\%20de\%20la\%2 0Cámara\%20de\%20Diputados\%201946-1955/_presentacion.asp.

${ }_{9}$ Diario de Sesiones de la Cámara de Diputados de la Nación (DSCD) (1946), 3 de julio.

${ }^{10} D S C D$ (1946), 23 de agosto.

${ }^{11} \operatorname{DSCD}$ (1946), 17 de julio y 8 de agosto; $D S C D$ (1947), 11 de junio; 18 de junio y 13 de agosto.
} 
aprobada por unanimidad, permaneció sin ser debatida. En 1947 declaró la incompatibilidad de Siri y del Secretario de Hacienda Roberto Tamagno por mantener relaciones comerciales con el municipio. ${ }^{12}$ Asimismo destacó que en alguna oportunidad el Presidente había aprobado el presupuesto proyectado por la Intendencia sin realizar observaciones, y condenó la discrecionalidad en el aumento de salarios de empleados municipales ya que sólo habían beneficiado a sectores jerárquicos. ${ }^{13}$ En una presentación conjunta con sus compañeros de bancada Alberto Candioti y Arturo Frondizi (ambos legisladores por la Capital Federal), López Serrot invitó una vez más al Ministro Borlenghi para que diera explicaciones sobre la prohibición de huelgas perpetrada hacia trabajadores de la Municipalidad, y pidió aclaraciones en relación a las medidas punitivas aplicadas a aquellos que habían realizado protestas. ${ }^{14} \mathrm{El}$ diputado se pronunció además sobre la utilización de materiales y empelados municipales por parte del peronismo con fines partidarios, mientras que a otras agrupaciones se les habrían negado sus peticiones para hacer uso de instalaciones, camiones sonoros y otros recursos oficiales. A su vez afirmaba que el Partido Peronista había infringido ordenanzas municipales al fijar carteles en edificios públicos, y que había instalado unidades básicas en locales de la Municipalidad. ${ }^{15}$ Un señalamiento similar realizó Francisco Rabanal, legislador por la Capital Federal. Indicó irregularidades en la construcción y adjudicación de viviendas colectivas por parte del oficialismo, afirmando que éste había hecho una utilización política de aquellas al establecer centros partidarios en algunas unidades. ${ }^{16}$

Durante el segundo mandato de Perón estas acusaciones no se detuvieron. En 1952 los radicales Emilio Ravignani y Manuel Belnicoff, ambos representantes por la Capital Federal, presentaron un proyecto de ley para que la Municipalidad capitalina se viera obligada a remitir cada 30 días a Diputados los decretos y su estado de cuentas. ${ }^{17}$ Por su parte, Belnicoff presentó un proyecto para designar a una comisión encargada de investigar las tareas administrativas del distrito, además de denunciar la exhibición de emblemas peronistas en oficinas municipales; invitó al Poder Ejecutivo a informar acerca de "si se ha dispuesto intervenir la Municipalidad de la Ciudad de Buenos Aires". ${ }^{18} \mathrm{El}$

\footnotetext{
${ }_{12}^{12} D S C D(1947), 11$ de junio.

13 Ibidem.

${ }^{14}$ Ibidem.

15 DSCD (1950), 31 de mayo.

${ }^{16}$ Ibidem.

${ }^{17}$ DSCD (1952), 11 y 12 de marzo.

${ }^{18}$ DSCD (1954), 24 de septiembre y 1 de diciembre.
} 
diputado por la Capital Federal Raúl Zarriello también insistió con ejercer un mayor control sobre la administración comunal. Propuso la publicación en el Boletín Municipal de todo proyecto que fuese tratado en el Congreso en relación al distrito ${ }^{19}$ y pidió a la Presidencia una copia de las actuaciones de la comisión investigadora de la Municipalidad. ${ }^{20}$ Por último, Alfredo Ferrer Zanchi (legislador por la Capital Federal) exigió un informe relacionado con la concurrencia obligatoria de empleados públicos a actos oficiales. ${ }^{21}$

Los legisladores de la Unión Cívica Radical presentaron varios proyectos a lo largo del período relacionados con el restablecimiento del Concejo Deliberante. En un principio el partido no propuso modificaciones a la ley orgánica en vigencia, sino que prefirió sólo insistir en su cumplimiento. En 1947 el diputado Oscar López Serrot presentó un proyecto que obligaba al Poder Ejecutivo a convocar a elecciones para restablecer el funcionamiento del Concejo. ${ }^{22}$ Acusaba al peronismo de violar la normativa al impedir la existencia de un gobierno comunal representativo y popular. Con preocupación denunciaba que tal situación se extendía a varias provincias. ${ }^{23}$ Presentaba al gobierno municipal como sinónimo de democracia, basándose en su rol histórico. Postulaba a los cabildos como antecedente, describiendo la instancia deliberativa como pilar del régimen democrático. En este sentido, destacaba que los abusos cometidos previamente en el Concejo de la Capital (de los cuales habían participado algunos concejales radicales) habían sido producto de las conductas desviadas de los hombres; dichas infracciones se contradecían con su carácter intrínsecamente democrático. Por eso es que el diputado se oponía a la erradicación de la legislatura local e insistía también en el reclamo de informes

\footnotetext{
${ }^{19} \operatorname{DSCD}(1955), 12$ de mayo.

${ }^{20} D S C D$ (1955), 8 de junio.

${ }^{21} D S C D$ (1955), 27 de julio.

${ }^{22} \operatorname{DSCD}(1947), 13$ de agosto.
}

${ }^{23}$ La obstaculización de la vida municipal bajo el primer peronismo fue una constante en muchas provincias y territorios nacionales. No nos detendremos en los casos particulares, pues excede el interés del presente trabajo. Para la situación general de las municipalidades véase Monjardín, Federico (1955). "Notas acerca del problema municipal argentino". In Definiciones Radicales, La Plata: UCR Intransigente, Comité de la Juventud Dr. Luis Dellepiane, t. I; para el caso de la provincia de Santa Fe véase Macor, Darío (2004). "Dinámica política y tradición constitucional: la reforma de 1949 en la provincia de Santa Fe". In Quinto sol, n.8, p. 51-72; para la provincia de Salta, Michel, Azucena del Valle (2005). "Salta y la reforma de su Constitución en 1949", In Cuadernos de Humanidades, n. 16; para los Territorios Nacionales, Arias Bucciarelli, Mario (2007). "El Peronismo clásico y los excluidos de la ley Sáenz Peña. Aportes para un debate desde los Territorios Nacionales". In XI Jornadas Interescuelas/Departamentos de Historia, Universidad Nacional de Tucumán; para la provincia de Buenos Aires, Recalde, Aritz (2010). Las municipalidades de la Provincia de Buenos Aires a través de la historia. ¿Autonomía o anarquía?. La Plata: Archivo Histórico de la Provincia de Buenos Aires. También se advierten las denuncias del diputado Mosset Iturraspe del Partido Demócrata Progresista, quien expresó la violación del artículo 5 de la Constitución Nacional por estar viviendo en "un país sin municipalidades". Afirmaba que el supuesto restablecimiento de la normalidad institucional era sólo un supuesto proclamado por el peronismo. DSCD (1946), 13 de septiembre. 
al gobierno nacional. A su vez invocaba al Congreso, a través de sus facultades de legislatura local, a implementar la regularización de los gobiernos comunales. Para sustentar la idea de violación al régimen municipal, López Serrot se valía del mencionado artículo 5 de la Constitución. Una vez más resultaba difícil determinar si a la Ciudad de Buenos Aires le correspondía contar con un gobierno local, pues no tenía rango de provincia. Además, si bien el diputado echaba mano del texto constitucional para esta justificación, no hacía mención de las disposiciones de la tesis restrictiva que entraban en aparente contradicción con lo expuesto. Contemplar estos artículos habría restado solidez a su argumentación, pues no dictaminaban el carácter necesario de un gobierno autónomo.

Un año después la bancada radical propuso una modificación a la ley vigente. En 1948 el diputado Francisco Rabanal proclamó la reapertura del Concejo, y además estableció una postura más atrevida al apostar a la elección directa del Intendente. ${ }^{24}$ Así se retomaba una iniciativa del partido que había sido frustrada en debates previos. ${ }^{25}$ En 1949 Rabanal solicitó además la derogación de aquellos decretos de 1943 que hubiesen afectado la normativa. ${ }^{26}$ Nuevamente el argumento central era que la vuelta al orden constitucional exigía el respeto por las instituciones democráticas, y esto significaba anular toda legislación de emergencia surgida del período de facto que impidiese el ejercicio del órgano legislativo local. En junio de 1950 Rabanal volvió a exponer el proyecto que había presentado dos años antes, pero tampoco esa vez logró su discusión.

En 1954, dadas las recurrentes irregularidades descritas, los diputados Manuel Belnicoff, Rodolfo Weidmann, Santiago Nudelman, Alende, Marcó y Carlos Perette firmaron conjuntamente un proyecto de declaración en el que postulaban la designación de una comisión que se abocara al estudio y diseño de un nuevo régimen comunal. Ese mismo año Belnicoff expresó una vez más la pretensión de hacer electivo el puesto de Intendente de la Capital Federal; para ello planteaba la necesidad de reformar la Constitución Nacional. Pretendía que esta condición estuviera explícita para sortear las flaquezas del texto vigente. ${ }^{27}$

\footnotetext{
${ }^{24} \operatorname{DSCD}$ (1948), 30 de junio.

${ }^{25}$ Para los debates y sanción de la ley orgánica municipal de la Ciudad de Buenos Aires en 1917 véase Privitellio (2003). Op. Cit.; Privitellio (2006). "Un gobierno reformado para una nueva ciudad: el debate de la ley municipal de 1917". In Korn, Francis y Romero, Luis Alberto (Comps.) (2006). Buenos Aires/Entreguerra. La callada transformación, 1914-1945, Buenos Aires: Alianza, p. 83-123.

${ }^{26} D S C D$ (1949), 20 de julio.

${ }^{27} \operatorname{DSCD}(1954), 1$ de diciembre.
} 
Por último, en 1955 el diputado Zarriello planteó la necesidad de reactivar el Concejo Deliberante. ${ }^{28}$ A su vez se fomentaba la iniciativa ciudadana para la elaboración de ordenanzas. Alcanzando el 30\% del padrón podían elevarse propuestas, exceptuando asuntos impositivos y presupuestarios. Se fijaban ciertas condiciones que, en caso de no ser cumplimentadas, hacían obligatorio un referéndum: si pasaban 60 días y la propuesta no era sancionada por la legislatura local; si dicha sanción comportaba modificaciones significativas; si el Ejecutivo comunal realizaba observaciones y el Concejo no se pronunciaba al respecto. También se establecía el referéndum con carácter obligatorio para los aumentos de tarifas y cuestiones vinculadas a los servicios públicos. Por último, la rama legislativa podía pedir un referéndum contando con el voto positivo de dos tercios del cuerpo; la Intendencia podía hacer uso de dicho instrumento cuando el Concejo rechazara sus propuestas. El resultado de la consulta popular tenía carácter vinculante y no podía ser modificado por ninguna de las ramas del gobierno local. Por otra parte, Zarriello formuló la posibilidad de revocatoria de los concejales por parte de los electores, siempre que éstos comprendieran el 30\% del padrón. Asimismo expuso que la rama legislativa podía suspender al Intendente por mayoría de dos tercios.

\subsection{Los proyectos peronistas: por la democracia, las potestades federales y la voluntad popular}

Por su parte, el oficialismo también se pronunció a propósito del escenario políticoinstitucional de la Ciudad de Buenos Aires. El 19 de octubre de 1946 el Presidente Perón remitió al Senado un proyecto en el marco del Primer Plan Quinquenal. La propuesta cuestionaba el funcionamiento previo de las instituciones de la Capital Federal, ya que afirmaba que en la práctica cotidiana lo dispuesto por la Constitución Nacional nunca se había aplicado estrictamente. La vaguedad del texto habría conducido a interpretaciones incorrectas, además de haber permitido la implementación de soluciones inicuas amparadas en la emergencia. Por eso el gobierno manifestaba que "el problema del régimen municipal aplicable a la Ciudad de Buenos Aires es uno de los que más preocupación han producido al Poder Ejecutivo y es propósito del mismo encararlo seriamente para ver si es posible llegar a una solución duradera dentro de la órbita de los

${ }^{28} D S C D$ (1955), 8 de junio. 
preceptos constitucionales". ${ }^{29}$ Tomando partido por la tesis restrictiva, Perón se inclinaba a sostener que, en calidad de Capital de la Nación, al distrito no le correspondían los mismos atributos que al resto de los estados provinciales. Proceder de este modo implicaba negarle a los poderes nacionales sus especiales competencias sobre la ciudad. Por lo tanto, la municipalidad podía perfectamente convertirse en una dependencia que respondiese directamente al Ejecutivo Nacional. Dicho postulado no debe encuadrarse solamente en la situación más general de construcción del liderazgo de Perón, pues es necesario detenerse en la especificidad del estatuto de la Ciudad de Buenos Aires. De este modo, Perón se inscribía en la larga tradición inaugurada por Roca a principios del siglo XX, en la cual tanto presidentes conservadores como radicales se habían anclado en sus facultades sobre la Capital. También agregaba que, desde el primer régimen comunal implantado en 1881 hasta la fecha de elaboración de su propuesta, "el régimen de la Capital Federal ha sido muy variado y no siempre de sistema electivo, sin que pueda decirse que en ello ha habido una intromisión indebida del Poder Ejecutivo". 30 Planteaba que habían tenido lugar alternadamente comisiones designadas por el Presidente y legislaturas electivas. Para reforzar su razonamiento, se valía del carácter democrático que el texto fijaba para todo sistema de gobierno. Consecuentemente, cuestionaba la legitimidad de origen de la comisión interventora de vecinos que se había desempeñado como una suerte de proto-legislatura entre 1941 y 1943, puesto que no había respetado el resultado de una votación popular. La mejor opción entonces la constituía el manejo efectivo por parte de las instituciones gubernativas nacionales: nadie se atrevería a negar que tanto el poder del Primer Mandatario como el que detentaba el Congreso Nacional derivaban de la soberanía del pueblo. Esta instancia también permitía evitar los comicios en el distrito. En la propuesta no se hacía mención a la ley 1.260 ni de la restauración del Concejo Deliberante, que bien podría haber sido otra alternativa para salvaguardar la expresión de los votantes. ${ }^{31}$

La naturaleza no electiva no vulneraba los principios asentados en la Constitución, tampoco lo hacía la ausencia de un gobierno municipal para la Ciudad de Buenos Aires.

\footnotetext{
${ }^{29}$ Diario de Sesiones de la Cámara de Senadores de la Nación (DSCS) (1946), 23 de octubre.

${ }^{30} \mathrm{Ibidem}$.

${ }^{31}$ Resulta curiosa la alusión al caso Washington, pues este ejemplo era usualmente esgrimido por los defensores de la tesis contraria. Al haber sido creada especialmente como capital, en la ciudad norteamericana no existía distinción entre la jefatura política y la administrativa. Por el contrario, y como se ha explicado anteriormente, en la Ciudad de Buenos Aires podía darse esta separación. Véase Passalacqua (1996). Op. Cit.
} 
Resulta interesante la justificación esgrimida por el justicialismo: "La Constitución argentina no establece regímenes municipales ni para la Capital Federal ni para las provincias. Únicamente en su art. $5^{\circ}$ se limita a señalar que cada provincia dictará para sí una Constitución que asegure, entre otras cosas, su régimen municipal'. 32 Por lo general se invocaba este artículo precisamente para hacer valer el derecho al gobierno comunal, como se ha expuesto en los argumentos de los diputados opositores. Sin embargo, en esta oportunidad se utilizó para robustecer una idea que se conducía en sentido contrario. Sobre la base de las explicaciones precedentes, el plan de reforma determinaba que la Intendencia sería ejercida por el Presidente, y podía delegar sus funciones total 0 parcialmente en alguno de los secretarios de la municipalidad designados por él, o bien en alguna otra persona de su libre designación. No se enunciaba la condición de acuerdo por parte del Senado. Las actividades otrora ejercidas por el órgano legislativo comunal quedarían a cargo del Congreso Nacional, que estaba facultado para delegarlas en una comisión bicameral conformada por diputados y senadores por la Capital Federal. Por último, el presupuesto para la ciudad sería elaborado por el Departamento Ejecutivo y precisaría de la posterior aprobación parlamentaria.

Transcurrido el tiempo reglamentario para la discusión de los proyectos, la propuesta elevada por el Poder Ejecutivo prescribió. En 1948 los senadores Pablo Ramella (por la Provincia de San Juan) y Alberto Teisaire (por la Ciudad de Buenos Aires) propusieron ciertas modificaciones al régimen municipal que no difirieron sustancialmente de las que contenía el Primer Plan Quinquenal. El Presidente nombraría un comisionado encargado de las funciones ejecutivas, mientras que el Congreso designaría una comisión para las labores legislativas. De este modo, quedaba eliminada nuevamente la instancia electoral para el gobierno local. Los legisladores no sólo sostenían su proyecto invocando la normativa constitucional, también afirmaban que "los antecedentes históricos, la doctrina dominante y el ejemplo de los Estados Unidos, en cuyo país rigen preceptos similares, llevan a descartar la existencia de un régimen municipal directamente representativo para la Capital Federal". ${ }^{33}$ Se remontaban a la ley dictada por la Asamblea Constitucional de 1826, que establecía que la Capital debía estar bajo el mando de las autoridades nacionales. Asimismo citaban a diversos autores y publicistas (Saavedra Lamas, Joaquín V. González y Zavalía, entre otros) que se pronunciaban a favor de dicha

\footnotetext{
${ }^{32}$ DSCS (1946), 23 de octubre.

${ }^{33}$ DSCS (1948), 21 de mayo.
} 
tesis. Siguiendo este razonamiento, la existencia de un gobierno autónomo para la Capital Federal iba a implicar la transgresión de los principios constitucionales.

\section{El espacio político local: discursos, prácticas e intereses en juego.}

Al analizar la propuesta peronista, una primera lectura ligera podría sugerir que existió una óptica administrativa al pensar al gobierno municipal como una fracción del gobierno nacional, noción que no confería entidad propia ni especificidad al espacio político porteño. ${ }^{34}$ No obstante, cabe destacar que las premisas expuestas por Perón distan de las argumentaciones de debates precedentes basadas en tales premisas. Por un lado, lejos están de aquella concepción de mediados del siglo XIX, que entendía al municipio como instancia administrativa y apolítica a partir de su condición de extensión natural de la familia y el ámbito privado. Por otra parte, tampoco se advierte el imperativo tecnocrático que supo primar en algunos discursos de los anos '20, que proponía que la gestión eficiente para una Buenos Aires moderna requería de funcionarios designados y por lo tanto no electos por sufragio popular. ${ }^{35}$ En la situación que aquí se considera, el justicialismo se valió del principio de legitimidad de origen para avalar su planteo. Así podía justificar la gestión del distrito federal como extensión de las dos ramas de gobierno nacional a partir de la legitimidad que la voluntad popular confería. Es preciso distanciarse entonces de una frecuente representación que se hace de Perón como un hombre pragmático cuyas acciones carecían de sustento ideológico. La doctrina justicialista, como así también sus discursos y obras, se nutrieron de diversas corrientes de pensamiento. Como señala Altamirano (2002), entre otros elementos pueden detectarse las nociones de 'libertad' y 'democracia'. Lo que resulta pertinente para nuestro trabajo es que dichos conceptos no fueron leídos en clave liberal, sino que adquirieron una inédita significación a la luz de otros paradigmas: ante la democracia y la libertad formales previas se planteaba que éstas sólo podían ser efectivas y verdaderas bajo las prácticas

\footnotetext{
${ }^{34}$ Para la discusión entre las perspectivas política y administrativa del gobierno municipal en el siglo XIX véase Ternavasio, Marcela (1991). Municipio y política: un vínculo conflictivo. Análisis histórico de la constitución de los espacios locales en Argentina (1859-1920). Tesis de Maestría - FLACSO, Rosario.

${ }^{35}$ Véase Privitellio (2006). Op. Cit.
} 
justicialistas. Entonces, si bien desde un plano discursivo se afirmaba que la verdadera democracia radicaba más en los derechos y beneficios sociales que en el voto, y contemplando que el sujeto al que se dirigía Perón era el pueblo como fuerza social más que el ciudadano individual, no debe asombrar la importancia otorgada a los comicios. Todo ritual político tiene la función de generar sentimiento de pertenencia y renovar la legitimidad de un régimen. En este sentido, podría comprenderse el acto electoral como oportunidad para actualizar la legitimidad más que como un momento de expresión de ciudadanía.

A pesar del declarado apremio por resolver la situación institucional de la Ciudad de Buenos Aires, el debate fue sistemáticamente retrasado. Diversas cuestiones que apremiaban a la Capital, como mejoras edilicias, saneamiento de predios, entre otras, fueron pasadas a archivo por caducidad al no ser tratadas en tiempo reglamentario. La dinámica parlamentaria descrita no se limitó a los problemas relacionados con la ciudad. Como se destacó previamente, el partido gobernante contaba con una amplísima mayoría en Diputados y con la totalidad de las bancas en la cámara de Senadores. Esta situación se consolidó tras la sanción de una nueva ley electoral en 1951, que fijó el sistema por circunscripciones combinado con voto uninominal. A su vez se aplicó el gerrymandering en algunos distritos electorales, adquiriendo el trazado de éstos formas insólitas. Dicha combinación aseguró la mayoría peronista, reduciendo consecuentemente la representación de minorías. Desde el oficialismo entonces no existieron mayores obstáculos para implementar algunos mecanismos a efectos de postergar aquellos temas que no consideraban de primordial importancia o que conllevaban alguna complicación. Una herramienta consistía en declarar a la Cámara en comisión para desplazar a consideración asuntos sin el previo despacho de las comisiones permanentes. Además era habitual la eliminación del tiempo reglamentario para consultas, o su aplazamiento para la sesión siguiente a fines de impedir que el bloque opositor pudiera explicitar sus declaraciones. Los registros de la actividad en el Congreso permiten también observar la recurrente formulación de mociones a favor del cierre de debates, o en pos de no dar lugar a los mismos a través del control del uso de la palabra. ${ }^{36}$ Si bien Luna (1987) y

\footnotetext{
${ }^{36}$ Otros autores han trabajado sobre la dinámica parlamentaria durante el período, véase: Luna, Félix (1987). Perón y su tiempo, Buenos Aires: Sudamericana, t. I, II y III; Waldmann, Peter (1981). El peronismo 1943-1955, Buenos Aires: Sudamericana; Ciria, Alberto (1983). Política y cultura popular: la Argentina peronista, 1946-1955, Buenos Aires: De la Flor; García Sebastiani, Marcela (2005). Los antiperonistas en la Argentina peronista. Radicales y socialistas en la política argentina entre 1946 y 1951, Buenos Aires: Prometeo; Persello, Ana (2007). Op. Cit.
} 
García Sebastiani (2005) sostienen que hasta 1948-1949 tuvo lugar la libre discusión y que la tarea parlamentaria fue muy fructífera, desde un principio pueden detectarse repetidos intentos por contener los cuestionamientos de la oposición, al menos en los aspectos que competen a la Ciudad de Buenos Aires. Por lo tanto, podría deducirse a partir de lo explicitado que los rasgos que adquirió la actividad parlamentaria en este período no permitieron que el Congreso ejerciera sus facultades como legislatura local con demasiada agilidad. Con el Concejo Deliberante inactivo y la falta de discusión de los problemas de la ciudad en el recinto, éstos aparentemente habrían sido resueltos a través del Departamento Ejecutivo sin una instancia deliberativa previa, situación que fue formalizada por la nueva Constitución del '49.

Estos retrasos dieron lugar a quejas por parte de la Unión Cívica Radical, cuyos miembros expresaban su preocupación por la vulneración de los regímenes municipales consagrados por la Carta Magna. En el caso particular de la Ciudad de Buenos Aires, la disconformidad ante esta actitud era más acentuada: los diputados radicales no concebían cómo el Congreso Nacional, órgano al que el texto constitucional encomendaba la legislación de la Capital, evadía el asunto. Paralelamente manifestaban las nocivas consecuencias que traía la falta de frenos y contrapesos producto de la ausencia del Concejo Deliberante. Esta carencia derivaba en una falta de control hacia el Departamento Ejecutivo, que obraba sin ningún tipo de vigilancia institucional.

Como se ha detallado, los argumentos de los radicales se basaban en reivindicaciones constitucionales y en alegatos a favor de la calidad democrática. No obstante, es preciso contemplar el capital político que la UCR había logrado acumular en la política local. ${ }^{37}$ Desde la reforma de la ley orgánica en 1917 hasta su suspensión en 1941, el Concejo había permitido a los dirigentes radicales establecer vínculos bastante más estrechos que los que podían consumarse a escala nacional. Justamente este tipo de conexiones, basadas en un acercamiento y eventual entrecruzamiento de las esferas social y política, dieron lugar a la emergencia de máquinas electorales y en algunos casos se consolidaron relaciones de patronazgo. A su vez, tanto la legislatura local como el control de los resortes del Departamento Ejecutivo, habilitaban a participar de negociados con el sector privado. De este modo, el hecho de no aplicar la ley orgánica significaba

\footnotetext{
${ }^{37}$ Para la política local de la Ciudad de Buenos Aires en los años '20 y '30 véase Privitellio (2003). Op. Cit.; Walter, Richard (1993). Politics and Urban Growth in Buenos Aires: 1910-1942, New York: Cambridge University Press; Gorelik, Adrián (1998). La Grilla y el Parque. Espacio público y cultura urbana en Buenos Aires, 1887-1936, Buenos Aires: Universidad Nacional de Quilmes.
} 
para el principal partido opositor mucho más que el debilitamiento de los principios democráticos, que en su discurso aparecían como elementos asociados históricamente a la propia agrupación. Al encontrarse inhabilitados para hacer uso de su peso político por vías institucionales en la Ciudad de Buenos Aires, los radicales se enfrentaban a la pérdida de recursos y relaciones que hubieran facilitado el mantenimiento de una sólida estructura montada en los años anteriores. En lo que concierne a la rama legislativa del gobierno porteño, tras su disolución y a pesar de las inmediatamente previas acusaciones de corrupción e ineficacia en las cuales los propios radicales se habían visto involucrados, algunos autores sostienen que el Concejo continuó siendo valorado como reducto democrático, tanto por la Unión Cívica Radical y el Partido Socialista como así también por algunas asociaciones barriales que supieron utilizar este órgano como vía para canalizar peticiones y reclamos. ${ }^{38}$

Por lo tanto, los obstáculos que el gobierno nacional imponía para la reapertura del órgano legislativo generaban el terreno propicio para que la Unión Cívica Radical reforzara su discurso a favor del respeto de la voluntad popular, subrayando la importancia de preservar el sistema democrático. Los radicales no sólo declaraban legal y justa la elección de los legisladores para la ciudad, sino que además hacían particular hincapié en su legitimidad; resultaba para ellos de particular importancia conservar el único elemento democrático con que podía contar el distrito.

Por su parte, el partido gobernante también adquiría ventajas específicas impidiendo el regular funcionamiento del gobierno local. Detrás de una alocución que destacaba la significación de la legitimidad de origen de los poderes nacionales, pueden advertirse algunas utilidades que traía el control sobre el gobierno de la ciudad. En primer lugar, el peronismo podía trasladar la instancia deliberativa al parlamento nacional, en el cual contaba con mayoría, lo que facilitaba el uso de recursos para trabar las iniciativas en la materia. Y a partir de 1949, la nueva Carta Magna permitió directamente anular el debate sobre asuntos de la Capital. Esto redundaba en la supresión de un ámbito que había sido conquistado previamente por otras agrupaciones partidarias: el espacio

\footnotetext{
${ }^{38}$ Para la posición de las sociedades de fomento véase De Privitellio (2003). Op. Cit.; García Sebastiani (2005). Op. Cit. También encontramos posiciones similares en entrevista a Gregorio Traub, miembro de la Junta de Estudios Históricos de Barracas y antiguo miembro de una sociedad de fomento de Barracas, julio de 2008. Para una perspectiva contrapuesta, que sostiene que el criterio predominante en las asociaciones barriales era el de la representación corporativa directa véase Gorelik (1998). Op. Cit.; Gonzáles, Ricardo (1990). "Lo propio y lo ajeno. Actividades culturales y fomentismo en una asociación vecinal. Barrio de Nazca (1925-1930)". In Mundo urbano y cultura popular. Estudios de historia social argentina, Buenos Aires: Sudamericana, p. 91-128.
} 
político-institucional de la Ciudad de Buenos Aires. A su vez, las circunstancias que atravesaba el régimen comunal condujeron al traspaso de prerrogativas a la Intendencia, cuya consecuencia fue una mayor concentración de los asuntos municipales en manos del gobierno nacional. No obstante, no puede afirmarse a priori la sumisión de estas cuestiones a la órbita de Perón. Varias investigaciones han demostrado que el sistema político peronista distó de ser monolítico y no se basó en un ciego verticalismo; tampoco puede afirmarse entonces que el Partido Peronista haya sido un cadáver político desde el momento de su conformación, pues debió atravesar un intrincado proceso hasta consolidarse como estructura unificada. ${ }^{39} \mathrm{En}$ el caso de la Capital Federal, por ejemplo en las políticas de vivienda, puede advertirse que prevaleció la falta de uniformidad entre las autoridades federales y locales, expresada en la coexistencia de distintos equipos técnicos y la carencia de un plan sistemático. ${ }^{40}$ También se han trabajado los complejos vínculos entre el poder nacional y la administración de la ciudad, que habrían impactado en la actividad municipal, estableciendo un corte alrededor de los años '48-'49 debido al pasaje del Partido Peronista de una estructura más abierta a un encuadramiento que supuso la disminución del debate entre sus miembros. ${ }^{41}$ De esta forma, las medidas aplicadas por el Ejecutivo Nacional habrían impactado fuertemente en el espacio político local. Aunque tal disposición pudo no haber conducido al dominio directo por parte del Presidente, la gestión de la Capital quedó en manos del oficialismo en carácter exclusivo. Esta pretensión puede ya detectarse en el proyecto inicial.

\section{A modo de conclusión}

$\mathrm{Ni}$ las mociones radicales ni los proyectos oficialistas lograron ser tratados en el Congreso por los motivos antes desarrollados. Es entendible que, contando con mayoría parlamentaria, el justicialismo no priorizara el debate de las iniciativas de la oposición. No obstante, resulta interesante destacar la contradicción entre un discurso que proclamaba

\footnotetext{
39 Para el proceso de conformación del Partido Peronista véase Mackinnon, Moira (2002). Los años formativos del partido peronista, Buenos Aires: Siglo XXI; Macor, Darío y Tcach, César (2003). La invención del peronismo en el interior del país, Santa Fe: Universidad Nacional del Litoral; Melón Pirro, Julio y Quiroga, Nicolás (2006). El peronismo bonaerense. Partido y prácticas políticas 1946-1955, Mar del Plata: Suarez. Para la consolidación de la estructura estatal durante el período véase Berrotarán, Patricia (2003). Del plan a la planificación. El Estado durante la época peronista, Buenos Aires: Imago Mundi.

${ }_{40}$ Véase Aboy, Rosa (2005). Viviendas para el pueblo. Espacio urbano y sociabilidad en el barrio Los perales. 1946-1955, Buenos Aires: Fondo de Cultura Económica.

41 Véase Ballent, Anahí (2005). Las huellas de la política. Vivienda, ciudad, peronismo en Buenos Aires 1943-1955, Buenos Aires: Universidad Nacional De Quilmes-Prometeo.
} 
un especial interés por la situación de la Capital Federal y una práctica que tendió a evadir la cuestión. Tampoco se cumplimentó con lo dispuesto por la ley en vigor. Consecuentemente, durante la década peronista no sólo el Concejo Deliberante de la Ciudad de Buenos Aires se mantuvo inactivo, sino que las irregularidades y abusos en la Municipalidad estuvieron a la orden del día hasta ser derrocado Perón en el '55. Además las cuestiones de la ciudad tampoco fueron debatidas en el Congreso, facultado para dicha tarea al menos hasta 1949.

La observación y análisis de la propuesta oficial, como así también las críticas y reclamos por parte de diputados opositores, permiten dilucidar un universo político muy rico que habilita a indagar más allá del aspecto estrictamente institucional, para percibir entonces una discusión más profunda acerca de los estatutos representativos. Esta polémica no fue privativa del período que se está analizando, pues se remonta a la instauración de los regímenes municipales en la Argentina. ${ }^{42}$ En el contexto de la Ciudad de Buenos Aires, el debate se vio actualizado cada vez que se originaron propuestas para reformular la legislación, como también en aquellas ocasiones en las que el Concejo se encontró anulado. De esta forma, en el presente trabajo se manifiesta relevante observar de qué modo esas nociones acerca de la representación se vieron resignificadas durante el peronismo. En el caso de la iniciativa del Primer Plan Quinquenal, en una primera aproximación podría percibirse una concepción de sus instituciones políticas como mera administración, pues el elemento electivo no estaba presente. Sin embargo, cuando se planteaba que su gobierno debía ser exclusiva responsabilidad de los poderes nacionales, el argumento no postulaba a la municipalidad como una repartición más. Por el contrario, se aclaraba que dicha disposición resultaba fundamental para salvaguardar la soberanía popular. Se distinguen entonces elementos democráticos en la justificación de la medida. A su vez, se invocaban las atribuciones especiales que concernían a los poderes nacionales en relación a la Capital de la República, enfatizando la relevancia de lo fijado por la Constitución Nacional. Por lo tanto, puede afirmarse que el oficialismo utilizó para hacer valer su propuesta los mismos postulados que la oposición esgrimía a la hora de denunciar al peronismo por su actitud referida al gobierno de la ciudad. A partir de aquí, deberá indagarse entonces en futuras investigaciones si existió correspondencia entre el discurso mencionado y las conductas políticas concretas que tuvieron lugar en la Ciudad de Buenos Aires.

\footnotetext{
${ }^{42}$ Véase Ternavasio (1991). Op. Cit.
} 
En cuanto al bloque opositor, observamos que también hacía referencia a los pilares democráticos en los reclamos por lo que denominaban la normalización del régimen comunal. No obstante, a diferencia de lo proclamado por el gobierno nacional, se reivindicaba en todo momento la necesidad de un gobierno autónomo y electivo (en una o en ambas ramas según el caso) para la ciudad. En este sentido, se abre también el interrogante acerca de la dinámica que adquirió la práctica política del radicalismo en el distrito, que seguramente se vio obligado a buscar modos alternativos al encontrarse despojado de un ámbito en el que había sido protagonista hasta no hacía muchos años.

\section{Referencias}

Aboy, Rosa (2005). Viviendas para el pueblo. Espacio urbano y sociabilidad en el barrio Los perales. 1946-1955, Buenos Aires: Fondo de Cultura Económica.

Ajmechet, Sabrina. "Diputados nacionales 1946-1955" en Materiales para la Historia Política, Centro de Estudios de Historia Política. Disponible en: http://www.unsam.edu.ar/escuelas/politica/centro_historia_politica/materiales/Conformació n\%20de\%20la\%20Cámara\%20de\%20Diputados\%201946-1955/_presentacion.asp

Altamirano, Carlos (2002). "Ideologías políticas y debate cívico". In Nueva Historia Argentina, Buenos Aires: Sudamericana, t. VIII, p. 207-255

Arias Bucciarelli, Mario (2007). "El Peronismo clásico y los excluidos de la ley Sáenz Peña. Aportes para un debate desde los Territorios Nacionales". In XI Jornadas Interescuelas/Departamentos de Historia, Septiembre, Tucumán.

Ballent, Anahí (2005). Las huellas de la política. Vivienda, ciudad, peronismo en Buenos Aires 1943-1955, Buenos Aires: Universidad Nacional De Quilmes-Prometeo

Berman, Romina (2010). "Un buen gobierno del distrito federal para la paz de la nación: reflexiones acerca del régimen municipal para la Ciudad de Buenos Aires en la reforma de la Constitución Nacional de 1949". In Segundo Congreso de Estudios sobre el Peronismo (1943-1976), Red de Estudios sobre Peronismo, Universidad Nacional de Tres de Febrero

Berrotarán, Patricia (2003). Del plan a la planificación. El Estado durante la época peronista, Buenos Aires: Imago Mundi.

Ciria, Alberto (1983). Política y cultura popular: la Argentina peronista, 1946-1955, Buenos Aires: De la Flor.

(2000). "Política tradicional y política de masas". In Romero, José Luis y Romero, Luis Alberto (Eds.) (2000). Buenos Aires, Historia de cuatro siglos, Buenos Aires: Grupo Editor Altamira, t. 2. 
Privitellio, Luciano de (2003). Vecinos y ciudadanos. Política y sociedad en la Buenos Airesde entreguerra, Buenos Aires: Siglo XXI.

(2006). "Un gobierno reformado para una nueva ciudad: el debate de la ley municipal de 1917". In Korn, Francis; Romero, Luis Alberto (Comps.) (2006). Buenos Aires/Entreguerra. La callada transformación, 1914-1945, Buenos Aires: Alianza, p. 83123.

Diario de Sesiones de la Cámara de Diputados de la Nación (1946 a 1955), Buenos Aires: Imprenta del Congreso de la Nación.

Diario de Sesiones de la Cámara de Senadores de la Nación (1946 a 1955), Buenos Aires: Imprenta del Congreso de la Nación.

García Sebastiani, Marcela (2005). Los antiperonistas en la Argentina peronista. Radicales y socialistas en la política argentina entre 1946 y 1951, Buenos Aires: Prometeo.

Gonzáles, Ricardo (1990). "Lo propio y lo ajeno. Actividades culturales y fomentismo en una asociación vecinal. Barrio de Nazca (1925-1930)". In Mundo urbano y cultura popular. Estudios de historia social argentina, Buenos Aires: Sudamericana, p. 91-128.

Gorelik, Adrián (1998). La Grilla y el Parque. Espacio público y cultura urbana en Buenos Aires, 1887-1936, Buenos Aires: Universidad Nacional de Quilmes.

Luna, Félix (1987). Perón y su tiempo, Buenos Aires, Sudamericana, t. I, II y III.

Mackinnon, Moira (2002). Los años formativos del partido peronista, Buenos Aires: Siglo XXI.

Macor, Darío (2004). "Dinámica política y tradición constitucional: la reforma de 1949 en la provincia de Santa Fe". In Quinto sol, n.8, p. 51-72.

Macor, Darío; Tcach, César (2003). La invención del peronismo en el interior del país, Santa Fe: Universidad Nacional del Litoral.

Melón Pirro, Julio y Quiroga, Nicolás (2006). El peronismo bonaerense. Partido y prácticas políticas 1946-1955, Mar del Plata: Suarez.

Michel, Azucena de Valle (2005). "Salta y la reforma de su Constitución en 1949". In Cuadernos de Humanidades, n. 16.

Monjardín, Federico (1955). "Notas acerca del problema municipal argentino". In Definiciones Radicales, La Plata: UCR Intransigente, Comité de la Juventud Dr. Luis Dellepiane, t. I.

Passalacqua, Eduardo H. (1996). "La autonomía de Buenos Aires. Un ensayo de historia institucional sobre las ideas y las formas de un cambio, y una tentativa de descripción. Resultados actuales y potenciales". In Ciudad de Buenos Aires. Gobierno y 
descentralización, Buenos Airess: CEA-Oficina de Publicaciones del CBC, Universidad de Buenos Aires.

Persello Ana (2007). Historia del radicalismo, Buenos Aires: Edhasa.

Recalde, Aritz (2010). Las municipalidades de la Provincia de Buenos Aires a través de la historia. ¿Autonomía o anarquía?, La Plata: Archivo Histórico de la Provincia de Buenos Aires

Ternavasio, Marcela (1991). Municipio y política: un vínculo conflictivo. Análisis histórico de la constitución de los espacios locales en Argentina (1859-1920). Tesis de MaestríaFLACSO, Rosario.

Waldmann, Peter (1981). El peronismo 1943-1955, Buenos Aires: Sudamericana.

Walter, Richard (1993). Politics and Urban Growth in Buenos Aires: 1910-1942, New York: Cambridge University Press.

Recebido para publicação em dezembro de 2012.

Aprovado para publicação em janeiro de 2013. 